\title{
UN RETRATO INÉDITO DEL CARDENAL ALFONSO DE BORJA EN UNA TABLA MARIANA DE GONÇAL PERIS SARRIÀ
}

\author{
MATILDE MiQuel JUAN \\ Universidad Complutense de Madrid
}

El estudio analiza la tabla principal de un retablo que representa a la Virgen con el Niño y al cardenal Alfonso de Borja arrodillado a sus pies de Gonçal Peris Sarrià, posiblemente destinado a la colegiata de santa María de Xàtiva. Palabras clave: Alfonso de Borja; Gonçal Peris Sarrià; gótico internacional; pintura sobre tabla; retrato.

\section{AN UNPUBLISHED PORTRAIT OF CARDINAL ALFONSO DE BORJA IN A MARIAN PANEL BY GONÇAL PERIS SARRIÀ}

This study is an analysis of the main panel of an altarpiece painted by Gonçal Peris Sarrià of the Virgin and Child with Cardinal Alfonso de Borja kneeling at their feet, possibly for the collegiate church of Santa Maria in Xàtiva. Key words: Alfonso de Borja; Gonçal Peris Sarrià; International Style; panel painting; portrait.

Los avatares de la historia han hecho que los investigadores nos centremos en unas obras de arte, releguemos otras a los almacenes de los museos, o dejemos en un limbo artístico piezas que nos miran con el ansia de ser observadas y estudiadas. Estas dos últimas circunstancias parecen concentrarse en una tabla que representa a la Virgen de pie con el niño Jesús, sosteniendo con su mano derecha una azucena, mientras que una figura de cardenal se representa arrodillado a sus pies, conservada en el Fine Arts Museum, de Boston (Estados Unidos). Cuatro ángeles músicos situados en las entrecalles flanquean la tabla central que, coronada por un óculo con el profeta David, está igualmente acompañada en los extremos superiores por los profetas Oseas y Ezequiel (fig. 1). La pieza que está pendiente de una restauración debió de ser la tabla central $(155.9 \times 77.4 \mathrm{~cm})$ de un retablo de unas dimensiones medias, es decir, de unos 3 metros de alto, por unas medidas similares de ancho. Este panel fue comprado por el Museo de Bellas Artes de Boston en 1929 al anticuario de Madrid Arthur Byne, que indicaba procedía de la catedral de Valencia, aunque en origen se ubicaba en la Colegiata de santa María de Xàtiva ${ }^{1}$.

1 Artículo realizado dentro del proyecto de investigación "La Génesis del Estado Moderno y el palacio especializado. Castilla y Granada en la Baja Edad Media”, aprobado por el Ministerio de Ciencia e Innovación (HAR200908901).

La bibliografía sobre la tabla: Post, 1933: 580-582; Nicholson, 1932: 60-67; Gaya Nuño, 1958: 258; Gómez Frechina, 2004: 96-99. Aún reconociendo el origen valenciano de la pieza ninguno de los investigadores vinculó al donante con el cardenal Alfonso de Borja. Agradezco a los doctores Carl B. Strehlke y Frederic Ilchman la posibilidad de consultar la documentación referida a la tabla de la Virgen con el Niño y donante del Museo de Arte de Boston. Entre la documentación de venta de la pieza está la carta que Arthur Byne escribe, y donde alude al origen setabense de la pintura: "The city of Játiva in the Province of Valencia became the vassal town of the powerful Borja family of Aragon whose chief had helped Don Jaime in the conquest of the Moorish Kingdom of Valencia. When Borja's descendants became cardinals and popes, under the Italianized name of Borja, they send Italian art and artist back to their native Valencia and specially favored their native town of Játiva. The primitive acquired by the Boston Museum was painted for the Collegiate Church of Játiva along with the several other Valencian primitives still in situ. When Játiva sunk into a mere unimportant village certain works of art were removed from the "colegiata" to Valencia and the painting in question was placed in the Cathedral where it lay hidden and forgotten. Recently when throught a cleaning-up this unappreciated Gothic picture came to light it was decided to sell it to defray the expenses of much needed repairs". Carta fechada el 18 de diciembre de 1929. Igualmente debo mostrar mi agradecimiento al investigador Josep Lluís Cebrian Molina por sus consejos y las interesantes conversaciones que hemos mantenido sobre Xàtiva y su patrimonio artístico. 


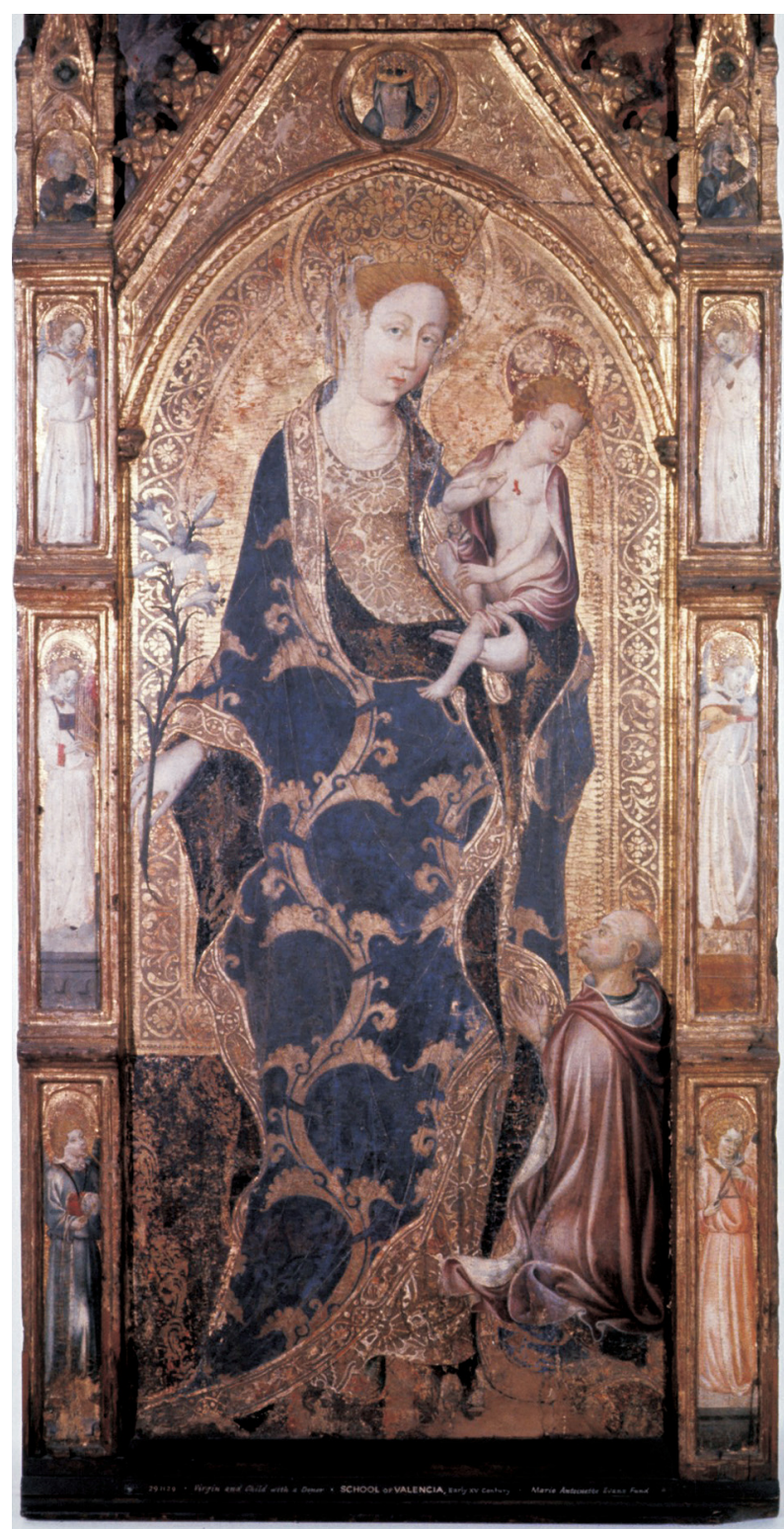

Fig. 1. Gonçal Peris Sarrià y taller, Tabla de la Virgen con el Niño y el cardenal Alfonso de Borja, ca. 1440-1451, temple y oro sobre madera, $155.9 \times 77.4 \mathrm{~cm}$, Museum of Fine Arts, Boston

(Maria Antoinette Evans Fund, 1929).

Por otra parte, gracias al doctor Carl B. Strehlke pude estudiar dos pequeñas tablas de dos entrecalles de un retablo que representaban a san Vicente mártir y a santa Catalina de Alejandría, y que ya los estudios de Russoli y Berenson ${ }^{2}$ atribuyeron a la personalidad del maestro del reta-

2 Russoli, 1962: s. p.

Arch. esp. arte, LXXXv, 340, octUBRE-DICIEMBRE 2012, 351-387, ISSN: 0004-0428 
blo de santa Bárbara de Puertomingalvo (MNAC), hoy relacionado con la figura de Gonçal Peris (fig. 2). La santa ataviada con un vestido de brocado y una túnica azul, sostiene en sus manos la palma y la rueda, mientras que san Vicente con la dalmática de diácono, porta la palma y la cruz en aspa, aludiendo a su martirio. A diferencia de otras figuras situadas en estos mismos espacios e identificadas con cartelas, parece que el reducido espacio de las piezas decidió al pintor a representarlas con sus símbolos martiriales y sobre un fondo dorado, sin elementos ambientales. Su mazonería se distancia de otros ejemplos conservados, puesto que el tradicional arco gótico polilobulado es sustituido por un arco de medio punto, con decoración estucada en el alfiz, que enmarca a los santos y que se vincula directamente con la mazonería de los ángeles de las entrecalles de la tabla de la Virgen del Museo de Bellas Artes de Boston ${ }^{3}$.

El elemento más significativo de la tabla de la Virgen con el Niño es el donante cardenal arrodillado. Aunque carece de otros símbolos propios de la jerarquía cardenalicia, el color púrpura del manto parece confirmar esta identificación. En este periodo son escasos los cardenales de origen valenciano, y cronológicamente sólo es posible atribuirlo a Alfonso de Borja, futuro papa Calixto III ${ }^{4}$. Alfonso de Borja nació en la Torre d'en Canals en 1378, fue obispo desde 1428, cardenal de los Quatri Santi Coronati en 1444, y Papa desde 1455 y hasta su fallecimiento en 1458. Quizá como agradecimiento por este nombramiento cardenalicio pudo encargar esta pieza, e incluso destinarla a su capilla funeraria donde se le representa a los pies de una Virgen portadora de una azucena, símbolo de la patrona de Xàtiva, lugar de procedencia de la familia Borja ${ }^{5}$. Posiblemente se trate del primer precedente de otros conjuntos donde el retrato de Alfonso de Borja se convierte en un hecho más que significativo, como sucede con el retablo de santa Ana, de Joan Reixach, para su capilla funeraria en la colegiata de Xàtiva en 1452 (Museo de la Colegiata de Xàtiva), y la tabla de la pinacoteca de Siena, de Sano di Pietro, donde aparece Calixto III pidiendo ante la Virgen del Popolo por la ciudad de Siena. Años más tarde, otro miembro de la familia Borja, el obispo Francisco de Borja, se retrataría en la tabla de la Virgen de las Fiebres atribuida a Pinturrichio (Museo de Bellas Artes, Valencia), y destinada a la capilla del mismo nombre de la Colegiata de Xàtiva ${ }^{6}$.

En 1933 Chandler R. Post publicó por primera vez esta tabla y la relacionó con el binomio Pere Nicolau- Marçal de Sas, y curiosamente no es hasta el 2004 que José Gómez Frechina en su estudio monográfico del retablo de san Martín, san Antonio y santa Águeda del Museo de Bellas Artes de Valencia vuelve a citar la pintura atribuyéndola a Gonçal Peris Sarrià. En el análisis de la pieza se advierten detalles como la gradación cromática empleada en el diseño de los cabellos de la Virgen y el niño, los esquemas decorativos de la túnica o la parte interior del

\footnotetext{
3 Son escasos los retablos conservados de Gonçal Peris Sarrià que contengan figuras en las entrecalles, se puede recordar la tabla de santo Domingo de Gonçal Peris y Guerau Gener, del Museo Nacional del Prado, el conjunto de los Gozos de la Virgen de Rubielos de Mora, o el de san Miguel, de la catedral de Murcia, que atestiguan su uso por el maestro, pero a la vez su excepcionalidad, y la peculiaridad de su diseño.

${ }^{4}$ Sobre los cardenales valencianos: Pons Alós, 2005. La figura carece del anillo y del capelo cardenalicio habitual en las representaciones de cardenal, pero el color púrpura del donante no deja lugar a dudas sobre su identificación con esta jerarquía eclesiástica. Las principales publicaciones sobre la vida del papa Calixto III: SANCHIS SIVERA, 1926: 241313; NAVARRO SORNÍ, 2003.

5 VIÑES MASIP, 1923.

${ }^{6}$ Son escasos los ejemplos conservados de tablas donde figuren los donantes de la obra durante la primera mitad del siglo XV en el reino de Valencia. Se pueden citar los casos del retablo de los Siete Sacramentos, donde fray Bonifacio Ferrer y su familia se representa en las piezas extremas de la predela, o el desaparecido retablo de san Miguel arcángel de la cartuja de Portaceli, donde aparecía el comitente Tomás Maza, ambos contratados por Starnina (Miquel Juan, 2007: 32-43). Cronológicamente la otra pieza sería esta tabla de la Virgen con el Niño con el cardenal Alfonso de Borja. En todos los casos citados existe una vinculación con el mundo italiano que pudo favorecer o propiciar este tipo de prácticas. De las últimas referencias sobre la pieza, con la bibliografía anterior: ORTENZI, 2008: 260-261.
} 

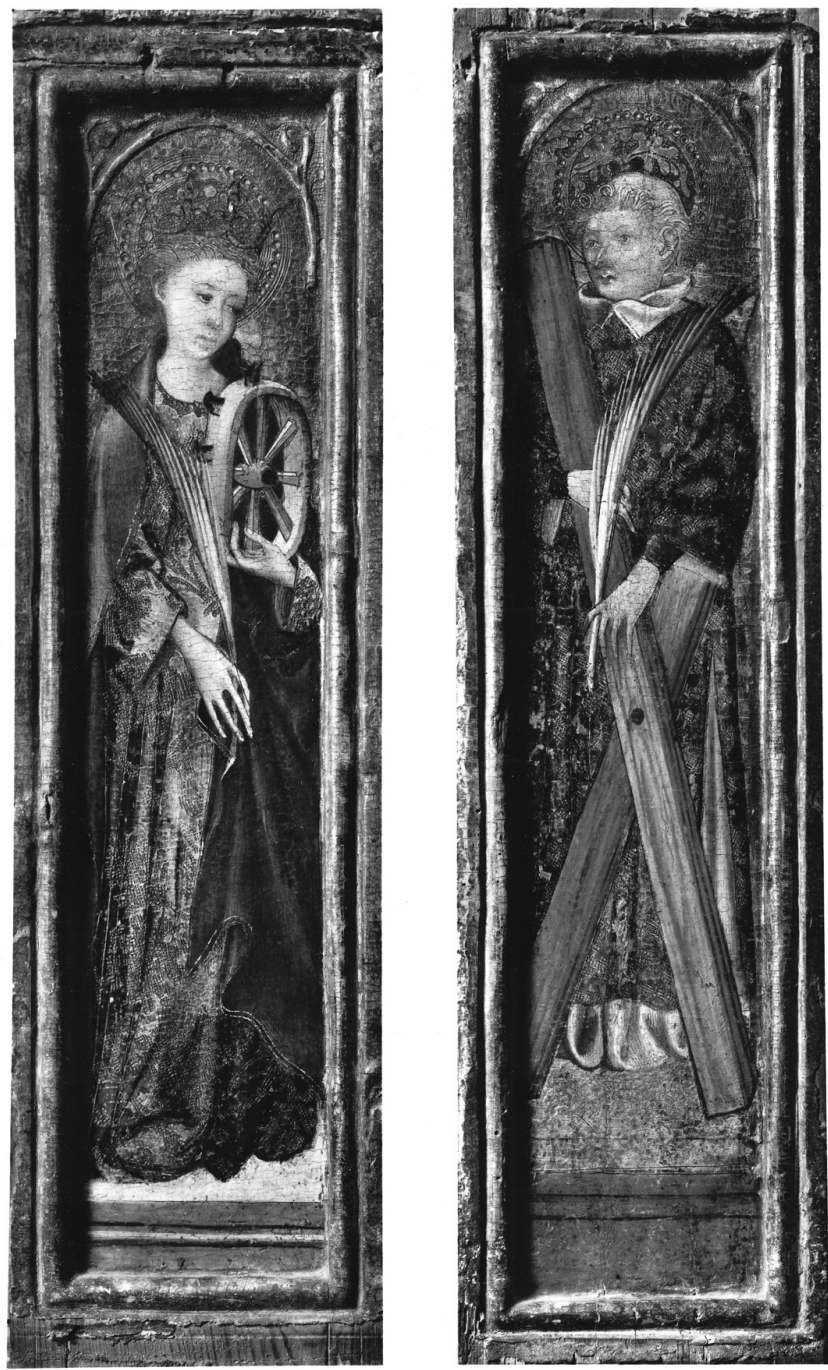

Fig. 2. Gonçal Peris Sarrià y taller, Tablas de santa Catalina de Alejandría y san Vicente Mártir, entrecalles, ca. $1440-1451$, temple y oro sobre madera, $44.8 \times 12.2 \mathrm{~cm}$ y $45 \times 12.1 \mathrm{~cm}$, respectivamente, Villa I Tatti, Florencia.

manto con el motivo de "les gallinetes", los dedos alargados, las bocas pequeñas, los rostros de la Virgen y santos son delicados y de tonalidades blanquecinas, o el uso del burilado en el manto y cenefa decorativa de enmarcación, que se vinculan a la actividad de Gonçal Peris Sarrià en la ciudad de Valencia. De hecho, la técnica del burilado fue especialmente empleada por Gonçal Peris Sarrià; a partir de unas pequeñas incisiones se juega y se combina con los dorados y los colores, creando un efecto tornasolado que en la oscuridad de la capilla se hace especialmente rico y especial, y que empleó de forma magistral en la tabla de san Clemente y santa Marta (1412, Museo de la catedral de Valencia), o en el san Bartolomé del Worcester Art Museum, entre otras. 
Sin embargo, en el retablo debieron participar otros miembros de su obrador bajo la supervisión de Gonçal Peris ${ }^{7}$. Sobre todo si se tiene en cuenta tanto el rostro de la Virgen, que no es el más frecuentemente empleado por el artista, como sobre todo la cronología de la tabla que en principio se debe circunscribir al año de 1444, fecha del nombramiento de Alfonso de Borja como cardenal, y el fallecimiento de Gonçal Peris Sarrià en 1451, correspondiente a la última etapa productiva del taller de Gonçal Peris, y en la que se puede apreciar documentalmente la colaboración de otros pintores, como pudo ser el caso del retablo de san Miguel Arcángel para la catedral de Murcia finalizado por Pere Guillem y Guillem Lagostera. Esta avanzada cronología coincidiría en estilo con otras piezas documentadas y conservadas como el san Miguel de Albarracín, fechado en 1437 (National Gallery of Scotland), y el retablo del arcángel san Miguel, en el caso de identificarlo con el conservado en el Museo de la Catedral de Murcia, de 1442-14448.

Se desconoce el lugar y fecha de nacimiento de Gonçal Peris Sarrià, aunque sus orígenes deben de ser valencianos. Su primera referencia segura data de 1401, y en 1404 aparece contratando un retablo junto a otros dos pintores. Es uno de los máximos representantes del segundo periodo del gótico internacional en Valencia. Como uno de los sucesores del obrador de Pere Nicolau asumió su clientela, la confección de retablos de tipo devocional y la colaboración con otros importantes maestros de la ciudad (Marcal de Sas, Guerau Gener, Joan Peris, Antoni Peris, o Jaume Mateu). Su actividad profesional abarca toda la primera mitad del siglo XV, y destaca por su amplitud, definida por 47 años de actividad profesional documentada, el gran número de piezas que confeccionó, alrededor de 38 , además de otros muchos conjuntos de tipo hagiográfico que se le atribuyen con bastante fiabilidad (como la santa Bárbara de Puertomingalvo, actualmente en el Museo Nacional de Arte de Cataluña, o la santa Lucia de Williams College Museum of Art, de Williamston), y su difusión más allá de las fronteras del reino de Valencia (el retablo de la Virgen para la catedral de Burgo de Osma, el san Miguel de la catedral de Murcia de 1442, otro bajo la misma advocación para la catedral de Albarracín en 1437, o el san Pedro y san Pablo destinado al monasterio de Piedra, en Cuenca, en el mismo año). Su estilo bascula entre piezas muy decorativas por la combinación de ricos y lujosos tejidos, y obras donde el maestro domina el color, y representa rostros bellamente dibujados o a veces grotescamente definidos. Al final de su trayectoria se adentra en las novedades flamencas, asumiendo como propias las recién llegadas innovaciones del norte, en el retablo de san Martín, santa Águeda y san Antonio (Museo de Bellas Artes, Valencia), o en el políptico mariano del Nelson-Atkins Museum, de Kansas City, principalmente ${ }^{9}$.

\section{Propuesta de reconstrucción (fig. 3)}

Las dimensiones de la pintura $(155,9 \times 77,4 \mathrm{~cm})$ son más reducidas que el de otras tablas principales de retablos que pueden alcanzar los $170 \mathrm{x} 90 \mathrm{~cm}$, y aluden a un políptico posiblemen-

\footnotetext{
${ }^{7}$ En el caso de las figuras de las entrecalles de santa Catalina y san Vicente, pertenecientes a la Villa I Tatti, la vinculación con la personalidad de Gonçal Peris parece más evidente: son detalles como la decoración vegetal del nimbo, el tipo de rostros, los brocados, la forma en la que caen los mantos, o el juego de dorados que emplea combinados con verde y rojo en la túnica de san Vicente.

${ }^{8}$ Miquel Juan, 2009: 49-55. Sobre el retablo de san Miguel de la catedral de Murcia todavía no se ha realizado un estudio que permita afirmar o rechazar su identificación con el contratado en 1442 por el presbítero Joan Álvaro, a través de su procurador el también presbítero Joan D’Alcaraz. La documentación no alude al destino de la pieza, y bien pudiera destinarse a la misma catedral, donde actualmente se encuentra. (CERVERó GOMIS, 1972: 47)

${ }^{9}$ Un análisis de su figura se puede encontrar en: Aliaga Morell, 1996; Miquel Juan, 2008: 145-147; García MARSILlA, 2009: 278-281.
} 
te dedicado a la Virgen de unos 3 metros de alto y algo similar, o un poco menos, de ancho. En la parte superior de esta calle central se representaría un Calvario, tema habitual en los conjuntos valencianos, y posiblemente confirmado por la vegetación de plantas que aún visible se aprecia en la parte superior.

Aunque es bastante probable que estuviera dedicado a los Gozos de la Virgen y que en las calles laterales se situaran las escenas gozosas de la vida mariana, la cronología avanzada del conjunto, así como la cercanía cronológica con el retablo conservado dedicado a santa Ana y destinado a la capilla funeraria de Alfonso de Borja en la Colegiata de Xàtiva (1452), puede hacernos plantear la hipótesis de un retablo bajo la advocación de la Virgen, en cuyas tablas laterales se situaran santos de especial veneración por Alfonso de Borja, como es el caso de santa Ana o san Calixto, los cuales estarían enmarcados por la representación de mártires de la devoción del cardenal Alfonso de Borja en las entrecalles, como es el caso de las piezas conservadas de santa Catalina y san Vicente de la colección de la Villa I Tatti, de Florencia ${ }^{10}$. La propuesta de reconstrucción que se hace atiende a la disposición de las figuras de santa Catalina y san Vicente mirando como era habitual al centro del conjunto, con una inclinación de cabeza que permite aproximarse a la altura que ocuparía la pieza dentro de las entrecalles.

\section{Destino del retablo}

A pesar del interés por desvelar más datos sobre el auténtico origen de esta pieza no ha sido posible llegar a una conclusión satisfactoria. Las dimensiones de la tabla, y por tanto del conjunto, parecen hacer referencia a una capilla, quizás el espacio funerario que el cardenal Borja pensó para el reposo de sus restos mortales ${ }^{11}$. La familia Borja tenía originalmente su lugar de enterramiento en la iglesia de san Francisco de Xàtiva, y aunque se tienen pocas noticias las reducidas dimensiones de la capilla debieron ser un importante óbice para que desempeñara el papel del espacio funerario de la nueva jerarquía eclesiástica del prelado. Esta intuición se corrobora por los intentos del entonces obispo de Valencia en 1437 de crear una capilla funeraria bajo la advocación de san Luis Obispo en la propia catedral de Valencia ${ }^{12}$. Se sabe que Gonçal Peris Sarrià recibió en febrero y junio de 1438 pagos por un retablo a través del presbítero Joan Ca-

\footnotetext{
${ }^{10}$ Se sabe que en la capilla de santa Ana instituida por el cardenal Alfonso de Borja en la Colegiata de Xàtiva, su hermana Juana, encargada de la dirección de las obras de la capilla, instituyó dos beneficios, uno bajo la invocación de san Agustín y san Ildefonso (santos que acompañan al conservado retablo de santa Ana, de Reixach), y otro a santa Ana y san Calixto, que quizás fueron los que pudieron ser representados en este otro conjunto (SANCHIS SIVERA, 1926: 291293). Aunque existen otras advocaciones como san Luis de Tolosa, que bien pudieron aparecer en el conjunto. Igualmente tanto santa Catalina como san Vicente fueron mártires especialmente vinculados a la figura de Alfonso de Borja, puesto que a partir de 1432 ordenó la devoción y culto a santa Catalina mártir en la diócesis valentina. El diácono san Vicente, junto con el obispo san Valero, fueron martirizados en Valencia, y ya desde época romana gozaron de una especial devoción en tierras valencianas, llegando hoy en día a considerarse uno de los patronos de la urbe.

${ }^{11}$ Existe abundante bibliografía sobre la faceta histórico-artística de la familia Borja, por lo que se opta por citar un estudio con la principal bibliografía anterior, que forma parte de una serie de publicaciones sobre el tema, y que aborda los principales espacios privilegiados de la familia Borja en Valencia, entre los que se citan las propuestas expuestas, y que amplían el contexto de mecenas de las artes de la familia Borja en el reino de Valencia: SERRA DesFiLis, 2006: 303- 328.

${ }^{12}$ Las referencias sobre este encargo son escasas, por lo que no estamos seguros de su finalización, teniendo además en cuenta que sería Rodrigo de Borja, futuro papa Alejandro VI, quien cumpliría la voluntad de su tío de dotar la capilla entre 1466 y 1486, a instancias del cabildo. La capilla estuvo dedicada a san Luis obispo debido a la llegada de las reliquias del santo traídas desde Marsella por Alfonso el Magnánimo. Sobre los primeros pagos del retablo: CERVERÓ Gomis, 1964: 107. Sobre la capilla en la catedral: SANChis Sivera, 1909: 267-270, 320; CARbonell Buades, 1995 : 68- 69; ARCINIEGA, 2001: 251-262.
} 


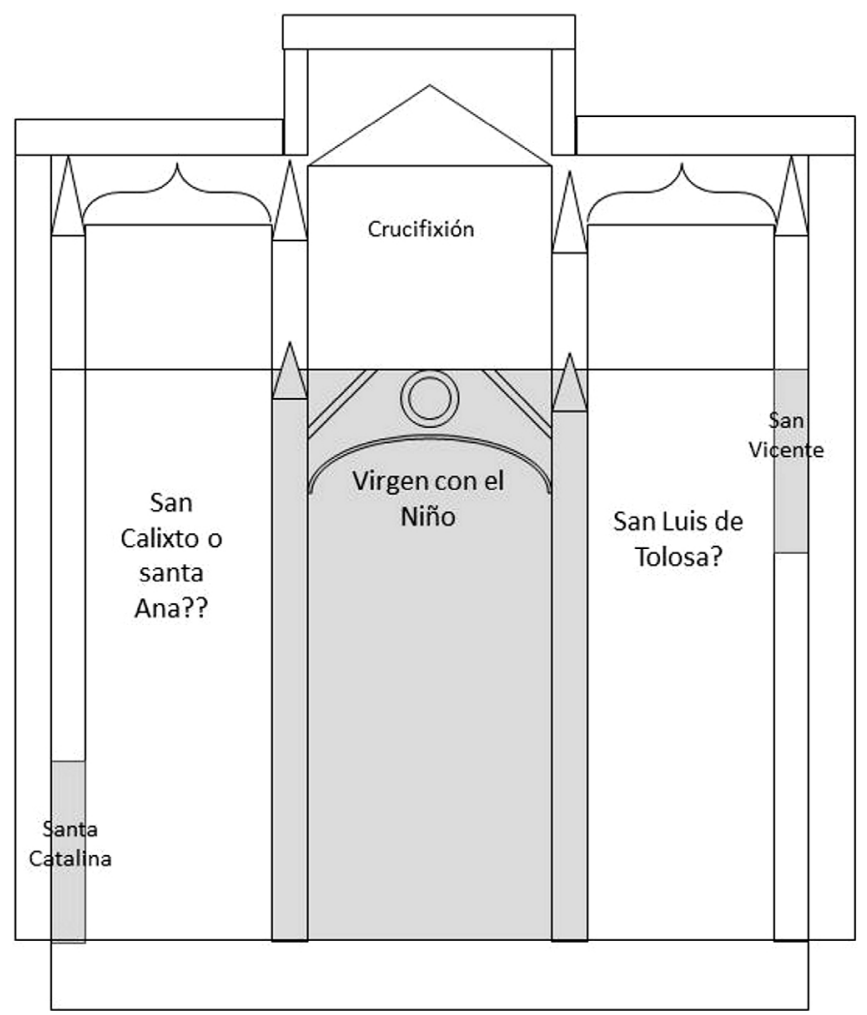

Fig. 3. Reconstrucción hipotética del retablo de la Virgen con el Niño y el donante cardenal Alfonso de Borja.

nou ${ }^{13}$. El tema del retablo no se detalla en las ápocas de pago, pero no debió de confeccionarse completamente puesto que entre 1466 y 1468 a solicitud del cabildo catedralicio, Rodrigo de Borja, sobrino de Alfonso, y futuro papa Alejandro VI, se encargó de concluir las últimas voluntades testamentarias de su tío, entre las que se cita la confección de un retablo a Rodrigo de Osona. La lentitud de las obras se debió a la construcción de la nueva librería entre 1438 y 1442 aneja a la capilla de san Luis, por lo que aunque los primeros pagos se realizasen en 1438 es probable que la confección del retablo se alargase a 1444, cuando ya era cardenal. Dicha capilla ha desaparecido, pero se ubicaba donde actualmente está la capilla de san Pedro (1696-1703). Esta hipótesis obligaría a adelantar la cronología de la tabla de la Virgen a 1440, ampliando el periodo de confección y la posible adscripción del conjunto a la catedral de Valencia.

Finalmente, y el que parece pudo ser el destino original del retablo es la colegiata de santa María de Xàtiva. Alfonso de Borja a partir de 1450 muestra su deseo de ser enterrado en la capilla setabense, y es en 1452 cuando termina Joan Reixach la pintura de un retablo para su capilla, que se conserva en la colegiata en la que se representa a santa Ana, la Virgen y el Niño en la tabla central, y en las tabla lateral derecha a san Ildefonso, con la figura de Alfonso a sus pies

13 Sanchis Sivera vincula este retablo de 1438 con el que finalmente su sobrino terminaría encargando en 1466 para el trasaltar de la capilla mayor, pero tanto el elevado pago de 11 libras, y de otros 130 florines en 1438, como el hecho de contratarse cuando firma el acuerdo de contruir su capilla funeraria, y su obligación de dotarla y embellecerla hace dudar de esta posible asociación que la documentación tampoco confirma. 
arrodillado, y a la izquierda san Agustín ${ }^{14}$. La voluntad de confeccionar una capilla funeraria en Xàtiva se pudo deber a los problemas existentes en la catedral de Valencia y su proyecto no terminado. Se desconocen los inicios de la capilla de santa Ana, pero es también posible que antes del retablo de Joan Reixac, Alfonso de Borja encargase un retablo para la colegiata en la que figurase como efigiado, el cual pudo ser reemplazado en 1452 con su nueva capilla funeraria ${ }^{15}$.

Esta hipótesis lo corrobora las palabras de Arthur Byne, vendedor de la tabla al Museo de Bellas Artes de Boston, que aludía a Xàtiva como lugar de origen de la pieza ${ }^{16}$, pero también la azucena en la mano de la Virgen, reconocida como patrona de Xàtiva. En la bibliografía sobre la población de Xátiva nada se indica de una tabla o retablo con estas características ${ }^{17}$. Si procedía de Xàtiva seguramente fue vendida a finales del siglo XIX cuando se acometieron las grandes obras de reforma del templo que desvirtuaron la imagen medieval, y marcaron el inicio de la dispersión de su patrimonio histórico ${ }^{18}$.

Con el ascenso al solio pontificio de Alfonso de Borja, con el nombre de Calixto III, sus intentos por dignificar una capilla que albergase en su tierra de origen sus restos mortales se vio relegada. Ni Valencia, ni Xàtiva preservan para la posteridad la memoria del primer papa español. Si originariamente tuvo su espacio funerario en el oratorio de san Andrea de la basílica Vaticana, desde 1610 tanto Calixto III como Alejandro VI reposan en la iglesia española de santa María de Montserrat en Roma ${ }^{19}$.

\section{BIBLIOGRAFÍA}

Aliaga Morell, Joan, Els Peris i la pintura valenciana medieval, Valencia, Alfons el Magnànim, 1996.

Arciniega, Luis, "La capilla de los Borja en la catedral de Valencia”, en Andaló, Learco; Mira, Eduard (comisarios), Los Borja. Del mundo gótico al universo renacentista, cat. exp., Valencia, Generalitat Valenciana, 2001, pp. 251-262.

Bérchez, Joaquín; Gómez-Ferrer Lozano, Mercedes, La Seo de Xàtiva: historia, imágenes y realidades, Valencia, Institut Valencià de Conservació i Restauració, 2007.

14 Este políptico fue encontrado en 1892 al desmontar el retablo de la antigua capilla de la Comunión, donde debió de ser trasladado con las obras de reforma de la colegiata, años en los que pudo encontrarse la tabla que se estudia y donde pasaría al mercado artístico. Uno de los últimos estudios, donde se puede encontrar la principal bibliografía sobre la tabla: GonZÁLEZ BALDoví, 2003: 214-219. Y sobre el debatido problema de la personalidad artística de Jacomart y Reixach en: GómEZ-FerRer LOZANO, 2006, pp. 71-99.

${ }^{15}$ El hecho de que fuera Joan Reixach, un pintor que se considera discípulo de Gonçal Perís Sarrià, el encargado de realizar un retablo para su capilla funeraria debe quizás considerarse como la continuación de una maestría y trabajos que fueron satisfactoriamente confeccionados por su maestro, con el que ya había mantenido contactos desde su etapa como obispo de Valencia. Tampoco es posible descartar la participación en esta tabla de la Virgen con el Niño de un jovencísimo Joan Reixach, puesto que las relaciones que presenta el rostro de la Virgen, y que lo distancian de Gonçal Peris, pueden asemejarse a las facciones de la santa Catalina de Villahermosa de Río, primera obra fechada y documentada de Joan Reixach, en 1448.

${ }^{16}$ Es conocida la labor de Arthur Byne como marchante y sus viajes por la península como comprador de obras de arte que vendería posteriormente al mercado norteamericano, principalmente, y al que debemos añadir esta pieza que ahora se estudia. Sobre su figura: MARTínez RuIz, 2005: 281-294; 2009: 328-341.

17 SARThou CARRERES, 1920-27.

18 El estudio más completo sobre la Colegiata de Xàtiva: BÉrChEZ; GómEZ-Ferrer LozAno, 2007.

19 Gallavotti Cavallero, 1997: 236-244. El traslado del cuerpo de Calixto III y Alejandro VI de la basílica de san Pedro a la iglesia de los españoles de santa María de Montserrat se deben a las grandes obras que afectaron al viejo templo de san Pedro iniciadas por Bramante, y que alcanzaron la capilla de san Andrea un siglo después.

Arch. esp. arte, LXXXV, 340, octUBRE-DiCIEMBRE 2012, 351-387, ISSN: 0004-0428 
Carbonell Buades, Marià, "Els papes Borja, l'art i la cultura”, en Xàtiva, els Borja: una projecció europea, cat. exp., vol. I, Xàtiva, Generalitat Valenciana, 1995, pp. 63-84.

Cerveró Gomis, Luis, "Pintores Valentinos. Su cronología y documentación”, Anales del Centro de Cultura Valenciana, n. ${ }^{\circ}$ 44, año XXV, 1964, pp. 83-136.

Cerveró Gomis, Luis, "Pintores Valentinos. Su cronología y documentación”, Archivo de Arte Valenciano, 1972, pp. 44-57.

Gaya Nuño, Juan Antonio, La pintura española fuera de España (Historia y Catálogo), Madrid, EspasaCalpe, 1958.

Gómez Frechina, José, El retablo de san Martín, sant a Úrsula y san Antonio Abad del Museo de Bellas Artes de Valencia, Madrid, BBVA, 2004.

Gómez-Ferrer Lozano, Mercedes: "Jacomart: revision de un problema historiográfico", en Hernández Guardiola, Lorenzo (coord.), De pintura valenciana (1400-1600). Estudios y documentación, Alicante, Instituto Alicantino de Cultura Juan Gil-Albert, 2006, pp. 71-99.

Gallavotti Cavallero, Daniela, "Sculture quattrocentesche provenienti dal vecchio san Pietro: Il monumento funebre di Callisto III Borgia”, en Sergio Rossi; Stefano Valeri (comisarios), Le due Rome del Quattrocento. Melozzo, Antoniazzo e la cultura artistica del'400 romano, Roma, ed., Lithos, 1997, pp. 236-244.

García Marsilla, Juan Vicente, "El precio de la belleza. Mercado y cotización de los retablos pictóricos en la Corona de Aragón (siglos XIV y XV)", en Denjean, Claude (ed.), Sources sérielles et prix au Moyen Âge. Travaux offerts à Maurice Berthe, Toulouse, Méridiennes, 2009, pp. 278-281.

González Baldoví, Mariano, "Joan Reixac o Pere Joan Reixac: Santa Ana, la Virgen y el Niño", en Ruiz Quesada, Francesc; Galilea Anton, Ana (comisarios), La pintura gòtica hispanoflamenca. Bartolomé Bermejo i la seva època, cat. exp., Barcelona, Museu Nacional d'Art de Catalunya y Museo de Bellas Artes de Bilbao, 2003, pp. 214-219.

Miquel Juan, Matilde, "Starnina e altri pittori toscani nella Valenza medievale", en Parenti, Daniela; Tartuferi, Angelo (ed.), Intorno a Gentile da Fabriano e a Lorenzo Monaco: nuovi studi sulla pittura tardogotica, Livorno, Sillabe, 2007, pp. 32-43.

Miquel Juan, Matilde, Retablos, prestigio y dinero. Talleres y mercado de pintura en la Valencia del gótico internacional, Universitat de València, Valencia, 2008.

Miquel Juan, Matilde, "El retablo de San Miguel Arcángel de Gonçal Peris Sarrià de la catedral de Albarracín”, Rehalda: Revista del Centro de Estudios de la Comunidad de Albarracín, n. ${ }^{\circ} 11,2009$, pp. 49-55.

Navarro Sorní, Miquel, Calixto III Borja y Alfonso el Magnánimo frente a la cruzada, Valencia, Ajuntament de Valencia, 2003.

Nicholson, Alfred, Art in America, XX, febrero 1932, pp. 60-67.

Ortenzi, Francesco, "Madonna delle Febbri, Pintoricchio", en Garibaldi, Vittoria; Mancini, Francesco Federico (comisarios), Pintoricchio, Milano, Silvana, 2008, pp. 260-261.

Pons Alós, Vicente, Cardenales y prelados de Xàtiva en la época de los Borja, Xàtiva, Centro de Estudios Borgianos, 2005.

Post, Chandler R., A History of Spanish Painting, vol. IV, part 2, Cambridge, Harvard University Press, 1933.

Martínez Ruiz, María José, "Luces y sombras del coleccionismo artístico en las primeras décadas del siglo XX: el Conde de las Almenas", Goya. Revista de Arte, n. ${ }^{\circ} 307-308,2005$, pp. 281-294.

Martínez Ruiz, María José, "La diplomacia española y estadounidense y su relación con el comercio de antigüedades en la primera mitad del siglo XX", Goya. Revista de arte, n. ${ }^{\circ} 329,2009$, pp. 328-341.

Russoli, Franco (ed.), La raccolta Berenson, Milan, Officine Grafiche, 1962, s.p.

Sanchis Sivera, José, La Catedral de Valencia, Valencia, Imp. F. Vives Mora, 1909.

Sanchis Sivera, José, "El Obispo de Valencia don Alfonso de Borja (Calixto III), (1429-1458)", Boletín de la Real Academia de la Historia, tomo LXXXVIII, 1926, pp. 241-313.

Sarthou Carreres, Carlos, Geografia General del Reino de Valencia, tomo 2, Barcelona, Alberto Marín ed., 1920-27.

Serra Desfilis, Amadeo, "Asuntos de familia: el arte patrocinado por los Borja en Valencia en tiempos de Alejandro VI", en Iradiel, Paulino; Cruselles, Jose M. " (coords.), De València a Roma a través dels Borja. Congrés conmemoratiu del 500 aniversari de l'any jubilar d'Alexandre VI, Valencia, Generalitat Valenciana, 2006, pp. 303-328.

Viñes Masip, Gonzalo J., La patrona de Játiva, Valencia, Hijo de F. Vives Mora, 1923. 